\title{
Specific interaction of citrate with bis(fluorophoric) bibrachial lariat aza-crown in comparison with the other components of the Krebs cycle $\dagger$
}

\author{
M. Paz Clares, ${ }^{a}$ Carlos Lodeiro, ${ }^{b}$ Damián Fernández, ${ }^{b}$ A. Jorge Parola, ${ }^{b}$ Fernando Pina, ${ }^{* b}$ \\ Enrique García-España, ${ }^{* a}$ Conxa Soriano $^{c}$ and Roberto Tejero ${ }^{a}$
}

Received (in Cambridge, UK) 19th May 2006, Accepted 11th July 2006

First published as an Advance Article on the web 3rd August 2006

DOI: $10.1039 / \mathrm{b} 607139 \mathrm{~b}$

Among the Krebs cycle components, just citrate enhances the fluorescence of a new bi(brachial) lariat aza-crown containing appended naphthalene fluorophores.

In recent years a great deal of experimental work has been devoted to molecular fluorescent chemosensors bearing polyamine chains as receptor units. The polyamine chains are extremely versatile, because depending on the protonation degree of the amine nitrogens, these receptors can bind either metal ions or anions. ${ }^{1}$ Although the number of available selective molecular chemosensors for metal ions is very large, there are not so many cases reported for the selective detection and/or quantification of anionic species. $^{2}$ A very important application of fluorescent chemosensors is Fluorescent Imaging, a powerful tool for visualizing the distribution of species in samples, with many applications in biological systems. ${ }^{3}$

In this respect, the possibility of discriminating one of the substrates among the others intervening in a metabolic route is very appealing. Several groups have advanced our knowledge on the recognition of citrate. ${ }^{4}$ Many of these works are based on positively charged, hydrogen bond groups or unsaturated metal centres coordinated to 1,3,5-trialkylbenzene scaffolds which direct such units towards the same side of the benzene ring adopting a "fly-trap" conformation.

In this communication we report on a new molecular structure that presents a specific fluorescent response for citrate in the 5-8 $\mathrm{pH}$ range. The other Krebs cycle components do not alter the fluorescence of the receptor at any $\mathrm{pH}$. Receptor (1) belongs to the category of bibrachial lariat aza ethers ${ }^{5}$ and is built up by $2+2$ condensation of two (2-aminoethyl)amine (tren) units each of which is functionalised with a methylnaphthylgroup, with 2,6pyridinedicarbaldehyde. This macrocycle can adopt folded

${ }^{a}$ Instituto de Ciencia Molecular, Departamento de Química Inorgánica, Universidad de Valencia, C/Dr. Moliner 46100, Burjassot (Valencia), Spain.E-mail: enrique.garcia-es@uv.es

${ }^{b}$ REQUIMTE-CQFB, Departamento de Química, Faculdade de

Ciências e Tecnologia, Universidade Nova de Lisboa, 2829-

516 Monte de Caparica, Portugal.E-mail: fjp@dq.fct.unl.pt

${ }^{c}$ Instituto de Ciencia Molecular, Departamento de Química Orgánica,

Facultad de Farmacia, Universidad de Valencia, Avda Vicente Andrés

Estellés s/n 46100, Burjassot (Valencia), Spain

$\dagger$ Electronic supplementary information (ESI) available: Fig. S1. Titration of compound (1), in the presence of the Krebs cycle components; Table S1. Intensity emission coefficients in the absence and presence of citrate; Fig. S2. Trajectories along the molecular dynamics calculations; Table S2. Stability constants of Krebs cycle compounds; Table S3. Protonation constants of Krebs cycle compounds. Experimental part on the potentiometric and photochemical measurements, molecular dynamics and comments on detection limit. See DOI: 10.1039/b607139b



Scheme 1 Chemosensor (1).

conformation with the two naphthylmethyl moieties capping upwards and downwards the macrocyclic cavity which would allow for a high interaction with encapsulated anionic substrates. ${ }^{6}$

The fluorescence emission of chemosensor (1) is reported in Fig. 1A. The general pattern of the spectra is similar to other bisnaphthalene systems linked by a polyamine chain, previously reported; a main band centered at $323 \mathrm{~nm}$, characteristic of the monomer naphthalene emission, accompanied by a broad and red shifted band that can easily be assigned to the excimer emission. ${ }^{6}$

As shown in Fig. 1A, addition of DL-isocitrate does not affect the shape and intensity of the spectrum. In contrast there is a significant increase of the fluorescence emission upon addition of citrate. The variations of the emission intensity in both monomer and excimer bands permit the calculation of the association constant between citrate and (1) at $\mathrm{pH}=6 \log K=4.9$ (Fig. 1).

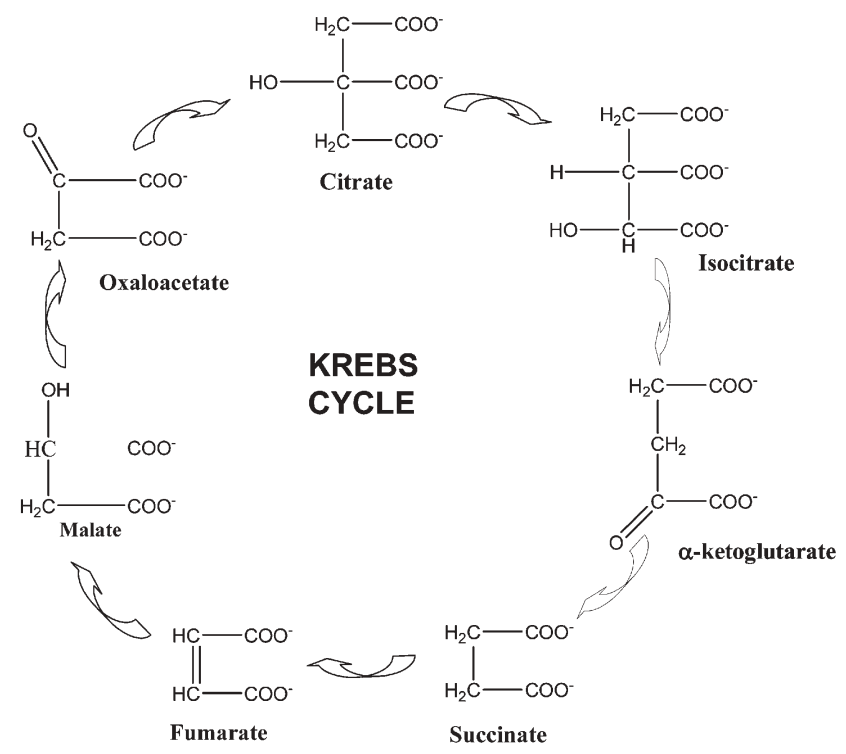





Fig. 1 A) Fluorescence emission spectra of chemosensor (1), $1 \times$ $10^{-5} \mathrm{M}$, in water at $\mathrm{pH}=5.8$. The spectra in the absence and presence of DL-isocitrate $3 \times 10^{-4} \mathrm{M}$, are coincident; B) the same in the presence of increasing quantities of citrate.

The experiments reported in Fig. 1 were also carried out for the other species present in the Krebs cycle, $\alpha$-ketoglutarate, succinate, fumarate, L-malate and oxaloacetate. In all cases no modifications in the emission spectrum of compound (1) were observed, see also Fig. S1† where the titration curves are presented. The main species responsible for the enhanced emission of (1) in the presence of citrate are $\mathrm{H}_{6}(\mathbf{1}) \mathrm{A}^{2+}$ and $\mathrm{H}_{5}(\mathbf{1}) \mathrm{A}^{2+}(\mathrm{A}=$ citrate $)$ as shown in Fig. 2 where the fitting of the fluorescence vs. $\mathrm{pH}$ curve has been performed taking into account the speciation studies performed by $\mathrm{pH}$-metric studies (vide infra and Table S1† for the fitting coefficents). The detection limit was calculated to be 10 micromolar corresponding to $c a .2 \mathrm{ppm}$, on the basis of a $10 \%$ error on the intensity of the emission signal (for quantitative comparisons see Supporting Materialit).

In spite of the lack of variation in the emission spectrum of (1) upon addition of the other components of the Krebs cycle, preliminary $\mathrm{pH}$-metric titrations show that (1) interacts to an

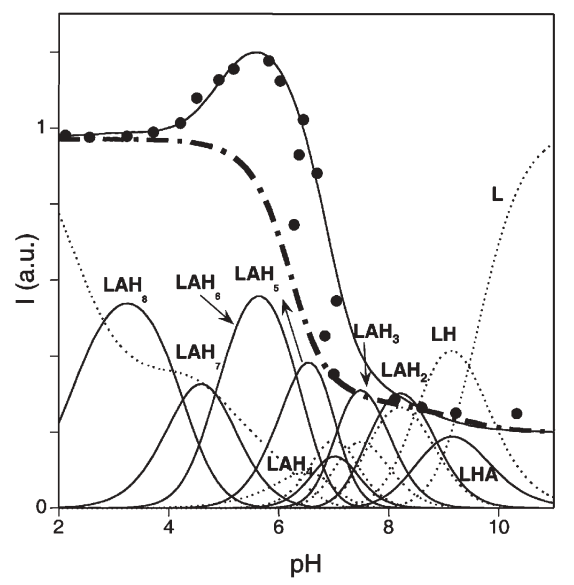

Fig. 2 Fluorescence emission titration curves of (1), $1 \times 10^{-5} \mathrm{M}$ in water, in the presence of citrate $1 \times 10^{-4} \mathrm{M},(\bullet)$ together with the respective mole fraction distribution: solid lines = citrate adducts; dotted lines $=$ free compound $(\mathbf{1})$. The other components of the Krebs cycle behave like free compound (1), dotted-point line (see supplementary material, Fig. S1†). important extent in water with all of them (Table S2 $\dagger$ ). ${ }^{7}$ Moreover, even though citrate is a tricarboxylic acid, it is one of the substrates having lower interaction with (1). Therefore, the magnitude of the binding constant does not seem to be a key point for explaining the luminescence of the system. In order to have an enhanced fluorescence at $\mathrm{pH}$ 6, the amino groups in the pendant arms of (1), which are the closest ones to naphthalene should be protonated at this $\mathrm{pH}$ preventing therefore the photoinduced electron transfer from the amines to the excited fluorophore. Hydrogen bonding between such ammonium groups and appropriately arranged acceptor groups may explain this behaviour. Citrate due to its bigger size and molecular structure would stay above the macrocyclic ring, blocking the arms through hydrogen bonding. This placement above the ring would on the other hand, explain the values of the binding constants found for the system. The smaller Krebs cycle components like succinate and L-malate would be in closer proximity to the macrocyclic cavity, gaining in affinity but losing efficiency in the formation of hydrogen bonds with the arms. The different arrangement of the functional groups in DLisocitrate would also permit a closer approach to the macrocyclic ring as denoted by its much higher affinity constants.

Molecular dynamics studies ${ }^{8}$ performed for the adducts resulting from the interaction of $\mathrm{H}_{6}(\mathbf{1})^{6+}$ with citrate, isocitrate and succinate support the above hypothesis. While in the system (1)-citrate a large population of minimum energy conformers shows the proposed exclusive binding of citrate (Scheme 2A), in the systems DL-isocitrate-(1) and succinate-(1) the greater percentage of minimum energy conformers shows the inclusive binding mode depicted, respectively, in Schemes 2B and 2C.

Fig. S2, in the supplementary material $\dagger$, shows the trajectories along the dynamics calculations ${ }^{8}$ of the distances between the carbon atoms of carboxylate groups and the nitrogen atoms of the amino groups in the arms for citrate, DL-isocitrate and succinate. It can be seen that while for citrate such distances have quite constant values of around $3 \AA$, for succinate such distances are over $5 \AA$ and for DL-isocitrate although there are populations with values of $c a$. $3 \AA$, most of the conformers present values over $5 \AA$ as occurred for succinate. Therefore, citrate will be the anion better suited for forming hydrogen bonds with the arms, thus enhancing the fluorescence.

Spanish MCYT under project No. BQU-2003-09215-CO3 and Portuguese FCT-MCTES under project No. POCTI/QUI/47357/ 2002 are acknowledged for financial support.

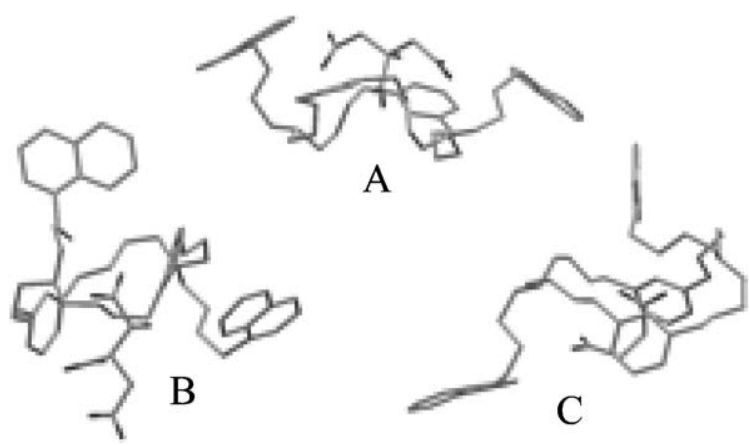

Scheme 2 


\section{Notes and references}

1 (a) B. Dietrich, Pure Appl. Chem., 1993, 65, 1457; (b) A. Bianchi, K. Bowman-James and E. García-España, Supramolecular Chemistry of Anions, Wiley-VCH, New York, 1997; (c) P. D. Beer and P. A. Gale, Angew. Chem., Int. Ed., 2001, 40, 486; (d) P. A. Gale, Coord. Chem. Rev., 2001, 213, 79; (e) C. A. Ilioudis and J. W. Steed, J. Supramol. Chem., 2001, 1, 165; (f) A. Bianchi, M. Micheloni and P. Paoletti, Coord. Chem. Rev., 1991, 110, 17; (g) R. Vilar, Angew. Chem., Int. Ed., 2003, 42, 1460; (h) J. M. Llinares, D. Powell and K. Bowman-James, Coord. Chem. Rev., 2003, 57, 240.

2 (a) S. Kubik, C. Reyheller and S. Stüwe, J. Inclusion Phenom. Mol. Recognit. Chem., 2005, 52, 137; (b) R. Martinez-Mañez and F. Sancenón, Chem. Rev., 2003, 103, 4419.

3 W. Mason, Fluorescent and Luminescent probes for Biological Activity, 2nd edn. Cambridge, UK, 1999.

4 (a) A. Metzger and E. V. Anslyn, Angew. Chem., Int. Ed., 1998, 37, 649; (b) S. L. Wiskur, H. Ait-Haddou, J. L. Lavigne and E. V. Anslyn, Acc. Chem. Res., 2001, 34, 963; (c) L. Fabbrizzi, F. Fotti and A. Taglieti, Org. Lett., 2005, 7, 2603; (d) D. Parker and J. Yu, Chem. Commun., 2005, 3141; (e) L. A. Cabell, M. D. Best, J. J. Lavigne, S. E. Schneider, D. M. Perreault, M.-K. Monahan and E. V. Anslyn, J. Chem. Soc., Perkin Trans. 2, 1991, 315; (f) V. N. Kozhevnikov, C. Mandl, S. Miltschitzky, A. Duerkop, O. S. Wolfbeis and B. Koenig, Inorg. Chim. Acta, 2005, 358, 2445; (g) Z. Lin, M. Wu, M. Schäferling and O. S. Wolfbeis, Angew. Chem., Int. Ed., 2004, 43, 1735.

5 (a) G. W. Gokel, Chem. Soc. Rev., 1992, 21, 32; (b) G. W. Gokel, L. J. Barbour, S. L. De Wall and E. S. Meadows, Coord. Chem. Rev,
2001, 222, 127; (c) V. J. Gatto, K. A. Arnold, A. M. Viscariello, S. R. Miller and G. W. Gokel, Tetrahedron Lett., 1986, 27, 327.

6 M. P. Clares, J. A. Aguilar, R. Aucejo, C. Lodeiro, M. T. Albelda, F. Pina, J. C. Lima, A. J. Parola, J. Pina, J. Seixas de Melo, C. Soriano and E. García-España, Inorg. Chem., 2004, 43, 6114.

7 The stability constants have been determined by $\mathrm{pH}$-metric titrations in $0.15 \mathrm{~mol} \mathrm{dm}^{-3} \mathrm{NaCl}$ at $298.1 \mathrm{~K}$ by means of the program HYPERQUAD (P. Gans, A. Sabatini and A. Vacca, Talanta, 1996, 43, 1739). Citrate: $\mathrm{A}+\mathrm{HL}=\mathrm{HAL}, \log K=3.69(1)$; $\mathrm{A}+\mathrm{H}_{2} \mathrm{~L}=\mathrm{H}_{2} \mathrm{AL}$, $\log K=4.09(1) ; \mathrm{A}+\mathrm{H}_{3} \mathrm{~L}=\mathrm{H}_{3} \mathrm{AL}, \log K=4.28(1) ; \mathrm{A}+\mathrm{H}_{4} \mathrm{~L}=\mathrm{H}_{4} \mathrm{AL}$, $\log K=3.92(2) ; \mathrm{A}+\mathrm{H}_{5} \mathrm{~L}=\mathrm{H}_{5} \mathrm{AL}, \log K=4.67(1) ; \mathrm{A}+\mathrm{H}_{6} \mathrm{~L}=\mathrm{H}_{6} \mathrm{AL}$, $\log K=4.71(1) ; \mathrm{HA}+\mathrm{H}_{6} \mathrm{~L}=\mathrm{H}_{7} \mathrm{AL}, \log K=4.21(1) ; \mathrm{H}_{2} \mathrm{~A}+\mathrm{H}_{6} \mathrm{~L}=$ $\mathrm{H}_{8} \mathrm{AL}, \log K=4.3(1)$. DL-Isocitrate: $\mathrm{A}+\mathrm{H}_{2} \mathrm{~L}=\mathrm{H}_{2} \mathrm{AL}, \log K=5.38(1)$; $\mathrm{A}+\mathrm{H}_{3} \mathrm{~L}=\mathrm{H}_{3} \mathrm{AL}, \log K=5.52(2) ; \mathrm{A}+\mathrm{H}_{4} \mathrm{~L}=\mathrm{H}_{4} \mathrm{AL}, \log K=5.79(2) ;$ $\mathrm{A}+\mathrm{H}_{5} \mathrm{~L}=\mathrm{H}_{5} \mathrm{AL}, \log K=6.01(2) ; \mathrm{A}+\mathrm{H}_{6} \mathrm{~L}=\mathrm{H}_{6} \mathrm{AL}, \log K=6.15(2) ;$ $\mathrm{HA}+\mathrm{H}_{6} \mathrm{~L}=\mathrm{H}_{7} \mathrm{AL}, \log K=5.79(2) ; \mathrm{H}_{2} \mathrm{~A}+\mathrm{H}_{6} \mathrm{~L}=\mathrm{H}_{8} \mathrm{AL}, \log K=$ 6.02(2). Succinic: $\mathrm{A}+\mathrm{HL}=\mathrm{HAL}, \log K=3.52(2) ; \mathrm{A}+\mathrm{H}_{2} \mathrm{~L}=\mathrm{H}_{2} \mathrm{AL}$, $\log K=4.41(1) ; \mathrm{A}+\mathrm{H}_{3} \mathrm{~L}=\mathrm{H}_{3} \mathrm{AL}, \log K=4.75(1) ; \mathrm{A}+\mathrm{H}_{4} \mathrm{~L}=\mathrm{H}_{4} \mathrm{AL}$, $\log K=4.85(1) ; \mathrm{A}+\mathrm{H}_{5} \mathrm{~L}=\mathrm{H}_{5} \mathrm{AL}, \log K=5.11(2) ; \mathrm{A}+\mathrm{H}_{6} \mathrm{~L}=\mathrm{H}_{6} \mathrm{AL}$, $\log K=5.31(1) ; \mathrm{HA}+\mathrm{H}_{6} \mathrm{~L}=\mathrm{H}_{7} \mathrm{AL}, \log K=5.32(1) ; \mathrm{H}_{2} \mathrm{~A}+\mathrm{H}_{6} \mathrm{~L}=$ $\mathrm{H}_{8} \mathrm{AL}, \log K=5.57(1)$

8 Dynamics calculations were performed using AMBER8 (D. A. Case, T. A. Darden, T. E. Cheatham, III, C. L. Simmerling, J. Wang, R. E. Duke, R. Luo, K. M. Merz, B. Wang, D. A. Pearlman, M. Crowley, S. Brozell, V. Tsui, H. Gohlke, J. Mongan, V. Hornak, G. Cui, P. Beroza, C. Schafmeister, J. W. Caldwell, W. S. Ross and P. A. Kollman, AMBER8, 2004, University of California, San Francisco) and AFF potentials (J. Wang, R. M. Wolf, J. W. Caldwell, P. A. Kolman and D. A. Case, J. Comput. Chem., 2003, 25(9), 1157) at 325 K. 